\title{
DIDACTIC PARAMETER OF LANGUAGE LITERACY IN THE BULGARIAN SECONDARY SCHOOL
}

\author{
Tanya Borisova ${ }^{1}$
}

\begin{abstract}
This article summarizes the main conclusions about the state of reading literacy of students in the same class in a Bulgarian school and the correspondence between the international criteria for establishing reading literacy of the students. A study, based on the longitudinal method, outlining the didactic parameters of reading literacy in the Bulgarian school was conducted. Emphasis is placed on the needed changes regarding overcoming the problems in the education in reading literacy of Bulgarian students, its limits and variety in its improvement; the correlations which exist between the results of the national external assessment (NEA) of the students in the subject of Bulgarian language and literature of the fourth, seventh and twelfth grade.
\end{abstract}

UDC Classification: 373; DOI: http://dx.doi.org/10.12955/cbup.v5.984

Keywords: Reading literacy, external State assessment, education in Bulgarian language and literature, level of reading literacy and language competency

\section{Introduction}

The use of the longitudinal method to establish reading literacy levels of students of the 4th, 7th, 9th and 12th grades, of the same class (enrolled in first grade in 2004) in the Burgas district, enabled the analysis of the reading literacy of the same class in the 4th, 7th, 9th and 12th grade with national and international means and traces the dynamics of the reading literacy of the students in all stages and grades of secondary school. The comparative analysis of the results obtained through the Bulgarian and international methods of research of the reading literacy shows reading literacy levels as a summary of the requirements of the new Bulgarian normative documents for studying Bulgarian language and the international standards for reading literacy;

The didactic parameters of reading literacy in the Bulgarian school outline the following trends:

\section{Purpose, object, subject and aim of the study}

The proposed dissertation work fulfilled the purpose and the tasks set in its concept and thus the following conclusions can be made:

1. The didactic parameters of the reading literacy, related to its formulation by UNESCO (UNESCO, 2006) read in the context of the state educational requirements for Bulgarian language and literature education in secondary school and compared to the PISA criteria should be basic in reading literacy education - from initial literacy education to reading comprehension and finding, retrieving and interpreting information from the text on the basis of established correspondences between the didactic parameters of the reading literacy in the Bulgarian secondary school and the international systems of work for raising the levels of its understanding.

2. The external evaluation in the fourth grade and the thorough analysis of its results in the Burgas district showed that the correct answers rates from 2007 to 2013 are still going downwards. In 2007 (with the first introduction of the fourth-graders test), the percentage of true answers was $81.01 \%$. The percentage in 2008 (the year of the evaluation) it was already $80.50 \%$. In 2013 it was only $68 \%$. Without further calculation, it can be said that the decline is significant, even on the basis of the overall results of the test, which is solved by the students. The difference of more than $13 \%$ can lead in several directions: - the achievements of the students have significantly dropped, i.e. their knowledge in Bulgarian language and literature marked a serious decline. In just six years something difficult to explain has happened in their education in Bulgarian language and literature The comparison of the 4th grade test of the 2007/2008 school year with the PISA criteria found the following: the text for dictation and reading is the same but is without subject; it is missing a title and it should be entitled by the students; only five of all 15 questions are to find and retrieve information from the text. They are standardized, i.e. the students choose a response from 3 possible options that are given to them. Moreover, the PISA criteria and their presence in the test lead to the conclusion that the state test for external evaluation can hardly be related to the global dimensions of reading literacy. The reference to the requirement for

\footnotetext{
${ }^{1}$ Trakia University, Faculty of Education, Stara Zagora, Bulgaria, borisova.t@abv.bg
} 
reading and writing education go hand in hand (as two branches of literacy) and this immediately reveals that more than $17 \%$ of the students did not master the so-called elementary initial literacy after the 4th grade.

2.1. According to the sex of the students, girls showed higher results. Their average score for girls is 17.29 points and for boys is 16.86 points. The difference is less than half a point. At the same time, $28.1 \%$ of the girls have reached the maximum test score, while the percentage of the boys is $17 \%$ according to data received from mean square deviation, there is significant difference.

2.2. More serious is the problem with the results obtained according to the students' mother tongue. The study shows that students whose mother tongue is Bulgarian have the highest score in the test and the dictation (average score 17.7 points). Students from Turkish ethnicity, who are predominant in the Burgas district in Ruen, Aytos, Pomorie, Malko Tarnovo, make more mistakes in observing the grammatical rules of the language and their score drops to 15.05 points. Statistically significant is the difference in the ball of the Roma ethnicity students - an average of 13.74 points. In the Burgas district they are predominant in the Kameno and Sungurlare regions. A difference of nearly 5 points in 20 max points of the students with Bulgarian as their mother tongue is enough to conclude that the Roma pupils show a significant lag in the covering of the state educational minimum standards still at the external evaluation in fourth grade. It is only emphasized on this part of the competences that are set out in the SER, for the purpose of applying knowledge rather than improving skills.

3. The external assessment of the same pupils in the seventh grade, consisting of two modules (with the first, compulsory for all students), which measured the pupils' achievements according to SER and the educational minimum, contains the following information for measuring the reading literacy of seventh grade students: - $18 \%$ of the points provide information on student literacy; $18,46 \%$ - bring information about students' achievements when editing text; the remaining $63.54 \%$ measure students' knowledge of grammar and literary comment only elementary literature forms. According to the PISA criteria, these percentages clearly show what and how is reading literacy being assessed according to the educational minimum. In this way of assessment, it turns out that only $51.23 \%$ of the seventh-grade students in the Burgas district have dealt with the tasks of the first module.

4. When compared to the average success rate of the same students from the external evaluation in 4th grade $-80.5 \%$ measured according to the average statistical dimensions of the Ministry of Education and Science (State educational standard). Referring to MES statements that these two tests - after the fourth and seventh grade measure how much and how many students have covered the SER in Bulgarian language and literature subject, without looking for a high level of difficulty, then the success of the same students marks a decrease of $29.97 \%$ for only three years.

5. The results of the study of the reading literacy of the seventh grade students show that the successful solving of the specific tasks within the depicted problem areas should be interpreted as a consequence of the change of the profile of the Bulgarian language teaching as the first language in the secondary school - from grammatically oriented towards communicative oriented Bulgarian language education; and not only to be talked about communication, but to make sense of it as a communication with a text, i.e. acquiring reading literacy and such skills that help the individual's social realization.

6. The study conducted and tested how and in what direction the reading literacy of the students of the same class in the fourth, seventh and ninth grade is moving. If in the fourth grade $81.1 \%$ of the students in the Burgas region are successful, according to the SER, in the same test in seventh grade $51 \%$ of them have managed to cope with the educational minimum. Somewhere between the fifth and the seventh grade, nearly $30 \%$ of the students "self-isolated" themselves from reading, and most of them have dropped out of school. The tendency for girls to do a little better than boys keeps up. These figures are very similar to the national statistics, because the Burgas region has always been somewhere in the middle with its achievements. In this case, this data should have been noticed by the MES long ago. But the results are reported year by year, and it has not occurred to them that they can already see the competencies of whole classes. And the competencies are decreasing. This is confirmed by the PISA criteria in a sample of 204 students from a grade, divided into different types of schools in the Burgas region. Still another 10\%, of the students are dropping beyond the critical level of reading literacy. So, from the fourth to the ninth grade, the succeeding students are reduced by half. This tendency is preserved till the twelfth grade and is confirmed by the results of the grade shown in the June 2016 
session of the Bulgarian matriculation exam in Bulgarian language and literature subject: - a large number of poor grades that were predicted from the study of reading literacy in the ninth grade; the lack of reading skills directly influences the acquisition of knowledge, so the students have limited themselves to working only on issues bearing 1 point for a correct answer (da Costa et al., 2013).

7. Research shows that the decreasing reading literacy in Bulgarian schools is a fact. Therefore, more correlations need to be sought to suggest to researchers and experts where they should direct their efforts if they want to get out of the enchanted circle. State schools most clearly indicate the tendencies in the achievement of the graduating students. They are the most, and in them the success gives an idea of the real level of literacy. In the Burgas region - 4, 33 / 4, 08, in the country 4,54 / 4,27. In these schools more than $89 \%$ of 12 th graders study. Most of the graduating students who have not worked on the creation of an interpretive text study at state schools. Most students also study there, also have not received higher scores from the range of 3,49 to 4,00. This is Grade Point Average of the students from the municipality schools compared with the same value achieved in the State and the private schools in Bulgaria. As a conclusion to their reading literacy, it can be argued that the differences are in contrast between profiled and un-profiled classes in the same school.

8. The decline in the dynamics of reading literacy is categorical and confirmed by the study.

\section{Results}

To overcome it, it is necessary:

- To take into consideration the level of the reading literacy of the students in the secondary school and to compare it with the requirements of the state educational standards for educational content (syllabus) through independent assessment methodology - threshold values, illustrative material (Bench mark), etc. It is especially important to integrate the skills that are a subject of evaluation in the international research;

- To understand why reading and reading skills are given such great attention in international studies of achievements in education. And if today our education system encourages the best students to acquire reading literacy, why do they continue their studies abroad and are realized in the societies there, while the labour market in Bulgaria remains with those that are below the critical values of the reading literacy;

- To respond to the broad public needs with reliable information on how our educated system prepares students for the Bulgarian public reality. The PISA's results can be the basis for public dialogue and political will, and for collaborating in defining and implementing educational goals with innovative methods that reflect the understanding of the skills necessary for the lives of mature people. The recognition of the literacy as understanding, use and comprehension for writing texts to achieve goals and meet the needs of deepening knowledge is essential for PISA. They see the literacy as a development of the intellectual potential of the person for his active participation in public life. Reading seeks to extract information, to interpret texts and to broaden their common understanding as well as to reflect on the text and to evaluate its content, form and characteristics (OECD, 2010).

- To process the educational context of a unified Europe the SER for learning content on the BLL in secondary school. These new standards should be applied in the practice of learning, as well as in the evaluation and measurement of students' achievements in Bulgarian language as the first and the national language in Bulgaria. A step in the right direction is the introduced external evaluation, but it waits for its improvements in the direction of validity and reliability (Mullis et al., 2004).

- To pay special attention to the thresholds for assessment of the BLL training between grades 4 and 5 as well as between 7 and 12 grade. There is also a need to define the BLL (mandatory, optional and facultative) levels of training, and why not to provide a specific discipline to develop the pupils' reading skills and reading literacy skills. Moreover, such experience exists in many European countries.

\section{Conclusions}

Among the key issues awaiting their decision are the following:

1. Establishing a link between the results of international researches in order to improve the Bulgarian language and literature education and the whole cultural and educational area, in order to build reading literacy among the students. 
2. Again, the problem of what to assess the external sight of the system is highlighted - the educational minimum or the achievements and weaknesses of the students in their reading literacy.

3. Where will the system of assessing students' achievements in Bulgarian language and literature go - to some Bulgarian idea or to the global system measuring a set of skills, including reading and writing, perception in their social context. (Rayner, K., \& Reichle, E.D., 2010) ${ }^{5}$

4. The published PISA reading literacy thresholds, tailored, compared and implemented through the normative documents for studying Bulgarian language and literature under the new School and Preschool Education Act, can be used as a basis for discussions on whether the FUNCTIONAL EDUCATON of Bulgarian students should be as a KEY COMPETENCY in the Bulgarian school (Lundberg \& Hoien, 1991).

5. The study of "reading literacy" also raises the question of how students should be trained in it to be validly assessed and prepared for social realization. Qualitative assessment, such as structuring evaluation standards, selecting an educational evaluation philosophy, and identifying key objectives, leads to the reconsideration of curricula in the Bulgarian language and literature and their focus on developing students' reading literacy.

\section{References}

da Costa, P.D., Almeida, P.A., Araújo, P. (2013). Reading Literacy in EU Countries: Evidences from PIRLS, JRC Scientific and Policy Reports, European Union.

Lundberg \& T., Hoien (1991). Literacy in a world of change. Stavanger: Center for Reading Research, UNESCO.

Mullis, I.V.S., Kennedy, A. M., Martin, M. O., \& Sainsbury, M. (2004). PIRLS 2006. Assessment Framework and Specifications. TIMSS\&PIRLS, International Study Center, Boston College.

OECD (2010). The high Cost of Low Educational Performance. Paris.

Rayner, K., \& Reichle, E.D. (2010). Models of the reading process. Wiley reviews: Cognitive Science, 1(6), 787-799.

UNESCO (2006). Education for All. Clobal Monitoring Report. Chapter: Understandings of literacy. Author, http://www.unesco.org/education/GMR2006/full/chapt6_eng.pdf 